\title{
Psychometric properties of the revised Piper Fatigue Scale in Dutch cancer patients were satisfactory
}

Citation for published version (APA):

Dagnelie, P. C., Pijls-Johannesma, M. C. G., Pijpe, A., Boumans, B. J., Skrabanja, A. T., Lambin, P., \& Kempen, G. I. J. M. (2006). Psychometric properties of the revised Piper Fatigue Scale in Dutch cancer patients were satisfactory. Journal of Clinical Epidemiology, 59(6), 642-649.

https://doi.org/10.1016/j.jclinepi.2005.09.015

Document status and date:

Published: 01/01/2006

DOI:

10.1016/j.jclinepi.2005.09.015

Document Version:

Publisher's PDF, also known as Version of record

Document license:

Taverne

Please check the document version of this publication:

- A submitted manuscript is the version of the article upon submission and before peer-review. There can be important differences between the submitted version and the official published version of record.

People interested in the research are advised to contact the author for the final version of the publication, or visit the DOI to the publisher's website.

- The final author version and the galley proof are versions of the publication after peer review.

- The final published version features the final layout of the paper including the volume, issue and page numbers.

Link to publication

\footnotetext{
General rights rights.

- You may freely distribute the URL identifying the publication in the public portal. please follow below link for the End User Agreement:

www.umlib.nl/taverne-license

Take down policy

If you believe that this document breaches copyright please contact us at:

repository@maastrichtuniversity.nl

providing details and we will investigate your claim.
}

Copyright and moral rights for the publications made accessible in the public portal are retained by the authors and/or other copyright owners and it is a condition of accessing publications that users recognise and abide by the legal requirements associated with these

- Users may download and print one copy of any publication from the public portal for the purpose of private study or research.

- You may not further distribute the material or use it for any profit-making activity or commercial gain

If the publication is distributed under the terms of Article $25 \mathrm{fa}$ of the Dutch Copyright Act, indicated by the "Taverne" license above, 


\title{
Psychometric properties of the revised Piper Fatigue Scale in Dutch cancer patients were satisfactory
}

\author{
Pieter C. Dagnelie ${ }^{\mathrm{a}, *, 1}$, Madelon C.G. Pijls-Johannesma ${ }^{\mathrm{b}, 1}$, Anouk Pijpe ${ }^{\mathrm{a}}$, \\ Brigit J.E. Boumans ${ }^{\mathrm{a}}$, Arno T.P. Skrabanja ${ }^{\mathrm{a}}$, Philippe Lambin ${ }^{\mathrm{b}}$, Gertrudis I.J.M. Kempen ${ }^{\mathrm{c}}$ \\ ${ }^{a}$ Department of Epidemiology, NUTRIM, Maastricht University, P.O. Box 616, 6200 MD Maastricht, The Netherlands \\ ${ }^{\mathrm{b}}$ Department of Radiation Oncology MAASTRO clinic-GROW, University Hospital Maastricht, P.O. Box 5800, 6202 AZ Maastricht, The Netherlands \\ ${ }^{\mathrm{c}}$ Department of Health Care Studies, CAPHRI, Maastricht University, P.O. Box 616, 6200 MD Maastricht, The Netherlands
}

Accepted 25 September 2005

\begin{abstract}
Objective: To examine the psychometric properties of the revised Piper Fatigue Scale (PFS) in Dutch cancer patients.

Study Design and Setting: Participants were 64 patients with lung (any stage, nonsurgery) and breast (any stage) cancer, selected for curative high-dose radiotherapy ( $\geqslant 50 \mathrm{~Gy}$ ). Prior to radiotherapy, patients completed the revised PFS (translated into Dutch), the Multidimensional Fatigue Inventory (MFI), and the Rotterdam Symptom Checklist (RSCL). Reliability and construct and criterion validity of the PFS were investigated.

Results: Overall, the structure of the Dutch revised PFS appeared appropriate, with corrected item-subscale correlations being higher than the correlations of the same item with the three other subscales; furthermore, internal consistency was excellent (Cronbach's $\alpha \geqslant 0.90)$. Lung cancer patients were significantly more tired then breast cancer patients, supporting construct validity. Criterion validity was also satisfactory, with highest correlations of PFS total fatigue with the MFI subscale general fatigue (0.84) and RSCL overall quality of life score (0.74). Internal consistency was similar in Dutch and U.S. breast cancer patients; fatigue scores were lower on several PFS subscales in the Dutch study population.

Conclusion: Psychometric properties of the Dutch version of the revised PFS, as tested in cancer patients prior to radiotherapy, were satisfactory. (C) 2006 Elsevier Inc. All rights reserved.
\end{abstract}

Keywords: Fatigue; Cancer; Piper Fatigue Scale; Validity; Reliability; Quality of life

\section{Introduction}

Fatigue can be considered as a subjective experience that affects every person from time to time. For healthy people, it can be considered as a protective, sometimes even pleasant, regular response to physical or psychological stress, which helps to maintain a healthy balance between rest and activity. For patients with specific diseases, however, fatigue often becomes a major symptom causing distress; for cancer patients, fatigue has been described as a major concern during treatment, both in advanced stages and after curative treatment. The numerous current definitions of fatigue are ambiguous and inconsistent, and vary across research studies [1,2]. Most authors consider fatigue in terms

\footnotetext{
${ }^{1}$ Authors' contribution to this article is equal.

* Corresponding author. Tel.: +31-43-3882374; fax: +31-43-2884128.

E-mail address: dagnelie@epid.unimaas.nl (P.C. Dagnelie).
}

of a complex subjective and multifactor construct with physical, mental, and psychological dimensions that are often associated with diminished quality of life (QoL) [2-5].

Fatigue is one of the most frequently reported symptoms in cancer patients [4,6-9]. Several authors have reported a high diversity of occurrence of fatigue across tumor sites $[8,10,11]$. Moreover, the prevalence of fatigue increases over the course of radiation therapy $[8,10,12-15]$. Lung cancer patients undergoing radiotherapy had the highest pre- and post-treatment levels of fatigue relative to patients of other tumor types [8]. A previous study [16] showed that both patients and oncologists reported the presence of fatigue in $75 \%$ of the patients; however, patients and oncologists disagreed on its importance- $61 \%$ of patients reported that fatigue affected their lives more than pain, but only $37 \%$ of oncologists reported that this was the case.

The measurement of fatigue with questionnaires has been the subject of many studies. The instruments used to 
evaluate cancer-related fatigue (CRF) are either on a single dimension, mostly assessing the presence or the intensity of fatigue (e.g., by means of a visual analog scale), or multidimensional, in which case fatigue is either incorporated as one of the domains of QoL or measured in an individual multidimensional CRF instrument.

Wu and McSweeney [5] evaluated the quality of existing instruments measuring CRF and concluded that the Piper Fatigue Scale (PFS) is the first validated and best-developed multidimensional measure of cancer-related fatigue. The PFS was developed from a thorough review of the literature on conception and measurement of symptoms in general and of fatigue and pain in particular [5]. The scale assumes that subjective perception is the key to understanding how fatigue varies between patients with cancer and healthy individuals [2]. With its strong theoretical foundation, Piper's integrated fatigue model makes the PFS unique among existing fatigue measures [5].

Initially, two forms of the PFS each used 0-100 visual analog scales to assess the feelings of temporal, intensity or severity, affective, sensory, evaluative, associated symptom, and relief components of fatigue experienced at two times: (a) 6 months prior to diagnosis or treatment and (b) at present. The early version of the PFS was criticized for its lack of clarity and length, limiting its application with patients who are very ill or tired [5]. The PFS was therefore revised as a shorter questionnaire, composed of 22 items on a 10-point numerical, self-report scale, based on data from a large cross-sectional, mailed survey [17].

The revised PFS has been described as one of the most well-developed and widely used instruments for assessing CRF [5]; it is used not only in the United States [18-20] but also in Europe, Asia, and Australia [21-24]. To facilitate cross-cultural comparisons between different countries and continents, especially the United States and European countries, we decided to translate the revised PFS into Dutch and to perform a validation study in a population of Dutch cancer patients in an early stage of treatment (i.e., preceding radiotherapy). Validation of the revised PFS in a Dutch patient population was considered important, because cultural differences in psychological adjustment and/or in the response to self-report questionnaires were reported in earlier studies [25-27]. So far, two non-U.S. validation studies of the revised PFS have been reported, one from France [21] and one from China [22].

The aim of the present study was to assess the psychometric properties (structure, reliability, construct validity, and criterion validity) of the revised PFS in Dutch cancer patients. In addition, we compared levels of fatigue in a Dutch and an American population of breast cancer patients. A Dutch version of the revised PFS was created for the present study. Feasibility and acceptability of the Dutch revised PFS, compared to other QoL assessment tools, are reported elsewhere [28].

\section{Materials and methods}

\subsection{Patients and procedure}

The study used a cross-sectional design to assess fatigue in patients with lung or breast cancer prior to radiotherapy. The study was conducted within the setting of the MAASTRO clinic, a large radiation oncology clinic situated in the cities of Maastricht and Heerlen in the southern part of The Netherlands. Patients had to meet the following inclusion criteria: any stage breast cancer or nonsurgery lung cancer; $>18$ years of age, and World Health Organization (WHO) performance status $0-2(0=$ fully active, asymptomatic; 1 = ambulatory; capable of carrying out work of a light or sedentary nature, such as light housework, office work; $2=$ in bed $<50 \%$ of the time: capable of self-care but not work). No additional inclusion or exclusion criteria were applied. Eligible were all patients who met these inclusion criteria and attended the MAASTRO clinic between June 2002 and October 2002 for high-dose radiation therapy. Over this period, 70 patients were invited to participate. Prior to initiation of radiotherapy, these patients were asked to complete a self-report questionnaire that included a demographic profile and a Dutch version of the revised Piper Fatigue Scale (PFS). In addition, two other instruments were included to assess aspects of criterion validity: the Multidimensional Fatigue Inventory (MFI), and the Rotterdam Symptom Checklist (RSCL). The study was approved by the institutional ethics committee, and both the patient and the radiotherapist or oncologist signed for informed consent.

\subsection{The revised Piper Fatigue Scale (PFS)}

The revised PFS in its current form [17] consists of 22 numerical items which assesses fatigue experienced at present. All items are coded on a 0-10 numeric scale. The revised PFS measures four dimensions of subjective fatigue: behavioral/severity (six items), relating to the severity, distress, and degree of disruption in activity of daily living; affective meaning (five items), relating to the emotional meaning attributed to fatigue; sensory (five items), relating to the physical symptoms of fatigue; and cognitive/mood (six items), relating to mental and mood states. To calculate subscale scores, the scores on all items within the particular subscale are added, and this sum is then divided by the number of items within the particular subscale. This gives a mean subscale score for the subject from 0-10 (minimal-maximal fatigue). A total fatigue score can be calculated by adding the four subscale scores and dividing this sum by four.

To translate the revised PFS into Dutch, three of us (G.I.J.M.K., B.J.E.B., P.C.D., native speakers of Dutch, with P.C.D. and G.I.J.M.K. also fluent in English) translated the PFS independently. Thereafter, these three independent translations were discussed in several consensus meetings of the authors (excepting only A.P. and P.L.). No backward 
translation was applied, because earlier experience of one of us (G.I.J.M.K.) indicated that the added value of this procedure would have been negligible. Apart from commonsense criteria such as legibility and clarity of concepts and wording, conceptual equivalence [29] was the primary criterion for judging equivalence of the Dutch translation with the original English version of the revised PFS. Wherever appropriate, we consulted the context-based EnglishDutch Van Dale dictionary [30].

\subsection{Analysis of psychometric properties of the revised PFS}

The essential psychometric elements of the PFS examined were structure, reliability, construct validity, and criterion validity.

To analyze the structure of the PFS (i.e., the consistency of items with other items within the same subscale, compared to items in other subscales of the PFS), we calculated corrected item-subscale correlations (i.e., correlations between item and sum score of remaining items of the same subscale), as well as correlations between each item and the other subscales of the PFS.

To examine the reliability of the Dutch PFS, corrected item-subscale correlations were used. Additional mutual correlations of all subscales were analyzed per tumor type. Cronbach's $\alpha$ was used to determine internal consistency for each of the resulting subscales as well as the total scale, in which the Dutch study was compared with the American study.

As an indication of construct validity of the Dutch PFS, the relationship between subscale scores and possible determinants of fatigue (i.e., tumor type and previous treatment with chemotherapy) was investigated. Construct validity was examined using hypotheses about how the PFS was expected to behave; that is, lung cancer patients were expected to have higher levels of fatigue than breast cancer patients $[3,8,31,32]$, and patients previously treated with chemotherapy were expected to have higher levels of fatigue than patients not treated with chemotherapy [33,34]. As an indicator of construct validity, differences in PFS scores between the mentioned subgroups of patients were calculated, and compared between the PFS and the general subscale of the MFI.

Criterion validity of the PFS was determined by correlating the scales with relevant subscales of two additional questionnaires: the MFI and the RSCL. These two questionnaires were chosen because both have been developed and validated in The Netherlands, have been published in the international scientific literature, and have frequently been used for studying fatigue and QoL in cancer patients in and outside The Netherlands. The MFI [35] is a 20-item questionnaire designed to measure multiple aspects of fatigue experienced during the last few days. The MFI measures scores on five subscales of four items each: general fatigue, physical fatigue, reduced activity, reduced motivation, and mental fatigue. Each item is rated on a five-point scale. The MFI has been extensively validated in cancer patients prior to radiotherapy $[8,35]$. In the present study population, we found Cronbach's $\alpha$-values for the relevant MFI subscales ranging from 0.79 to 0.91 .

The RSCL [36] is a 39-item questionnaire that assesses symptoms during the preceding week. The RSCL measures scores on four domains: physical symptom distress (23 items), psychological distress (seven items), activity level (eight items), and overall valuation of life (one item). Each item is rated on a four-point scale. For reasons of feasibility and ethics (length of questionnaire), the domain 'physical symptom distress' was left out of the present study. The RSCL has been extensively used and validated in different groups of cancer patients [36,37]. In the present study population, Cronbach's $\alpha$ of the relevant RSCL subscales ranged from 0.90 to 0.93 .

\subsection{Statistical analysis}

If one item was missing in a subscale, it was substituted by the subject's mean score on the other items within that subscale. Additional analyses showed that, for the analysis of internal consistency (Cronbach's $\alpha$ ), results were similar when missing values were or were not substituted. For no subject were there $\geqslant 2$ items in a subscale missing.

In examining reliability and criterion validity of the PFS, Pearson's correlation coefficients were calculated, and Student's $t$-test was used to test differences between subgroups of patients (construct validity). Additional analyses showed that results were similar when distribution-free statistics (Spearman's rank correlations and Mann-Whitney $U$-test, respectively) were used. Data analyses were performed using SPSS for Windows, version 11.0 (SPSS, Chicago, IL, USA). The level of statistical significance was set at 0.05 (two-tailed test).

\section{Results}

\subsection{Study population, participation, and response}

Out of 70 invited patients, 6 patients (of whom 5 were lung cancer patients) refused to cooperate because of being too tired; the remaining 64 patients $(91 \%)$ signed for informed consent and completed the questionnaire. Not all PFS questions were answered by all patients; for example, item 4 ("To what degree is the fatigue you are feeling now interfering with your ability to engage in sexual activities") was left unanswered by $14 \%$ of patients, and item 10 ("To what degree would you describe the degree of intensity or severity of the fatigue which you are experiencing now as being: Positive-Negative") by $11 \%$ of patients.

Patient characteristics are presented in Table 1. All breast cancer patients and none of the lung cancer patients had been previously treated with surgery (not tabulated); 15 of 29 of the lung cancer patients (52\%) had been previously 
Table 1

Demographic and clinical data of participating patients $(n=64)$

\begin{tabular}{lll}
\hline Characteristics & Lung cancer & Breast cancer \\
\hline Sample size & $n=29$ & $n=35$ \\
Median age, years (range) & $69(46-88)$ & 58 (39-82) \\
Gender, no. & & \\
$\quad$ Male & 16 & 0 \\
$\quad$ Female & 13 & 35 \\
Tumor stage, no. & 4 & \\
I & 5 & 23 \\
II & 10 & 9 \\
III & 1 & 1 \\
IV & 6 & 0 \\
SCLC ld & 3 & 2 \\
Unknown & & \\
Prior chemotherapy, yes/no & 15 & 9 \\
$\quad$ Yes & 14 & 26 \\
$\quad$ No &
\end{tabular}

Abbreviation: SCLC ld, small cell lung cancer-limited disease.

treated with chemotherapy, compared with only 9 out of 35 breast cancer patients $(23 \%)$.

\subsection{Structure}

As shown in Table 2, consistency was adequate, with none of the corrected item-subscale correlations being lower than the correlations between the item and the three other subscales. Corrected item-subscale correlations were high for all subscales, and highest for the subscale affective meaning; correlations were slightly lower for the subscale cognitive/mood (Table 2).

Correlations of the total fatigue scale with the PFS subscales were higher in breast cancer patients than in lung cancer patients (Table 3). When compared to U.S. breast cancer patients, correlations between subscales in breast cancer patients in our study were slightly higher for most subscales (Table 3).

\subsection{Reliability}

Internal consistency as assessed by Cronbach's $\alpha$ (Table 4) was 0.93 for the total fatigue scale in lung cancer patients, and 0.97 in breast cancer patients. For all subscales, Cronbach's $\alpha$ 's for breast cancer patients were somewhat higher than for lung cancer patients. Cronbach's $\alpha$ 's in U.S. and Dutch breast cancer patients were quite similar (Table 4).

\subsection{Construct validity}

As shown in Fig. 1, lung cancer patients were significantly more tired than breast cancer patients, both on the total fatigue scale and all subscales of the PFS ( $P$-values ranged from $<0.001-0.009)$. Prior treatment with chemotherapy was associated with higher fatigue on the PFSsubscale behavioral/severity (mean \pm SE: $5.21 \pm 0.57$ and $3.15 \pm 0.47$ for previously treated and untreated patients, respectively; $P=0.008)$. The general subscale of the MFI showed a very similar pattern: on the MFI, fatigue was significantly $(P<0.001)$ higher in lung cancer patients than in breast cancer patients. The MFI also showed a tendency for higher fatigue levels in patients previously treated with chemotherapy, compared to chemotherapy-naïve patients; however, the difference did not reach statistical significance $(P=0.10)$.

\subsection{Criterion validity}

Pearson's correlations of the PFS total fatigue score with the MFI and RSCL subscales were moderate (range 0.490.84) (Table 5). As expected, the PFS total fatigue score correlated highest with the MFI subscale general fatigue (0.84) and lowest with the MFI subscale mental fatigue (0.49) of the MFI. The PFS total fatigue score correlated well with the overall QoL score of the RSCL (0.74). The highest correlation with the RSCL was found between the PFS behavioral/severity subscale and the RSCL overall QoL score (0.78).

\subsection{Comparison of fatigue levels in Dutch and U.S. breast cancer patients}

Mean fatigue scores on the subscales sensory and cognitive/mood were lower in our study population of Dutch breast cancer patients than in a U.S. breast cancer study population [17] (Fig. 1; $P<0.01$ ). For the other subscales and the total fatigue scale, the difference was not statistically significant.

\section{Discussion}

The present study was aimed at investigating the psychometric properties of a Dutch version of the revised Piper Fatigue Scale. Prior to radiotherapy, 64 Dutch lung and breast cancer patients completed a questionnaire, which included the newly translated Dutch version of the revised PFS, the MFI, the RSCL, and a demographic profile. We found that the Dutch version of the revised PFS was reliable, was able to discriminate between groups, and gave a good indication of the level of fatigue of patients in several domains. In addition, we compared the levels of fatigue in the Dutch study population of breast cancer patients with a U.S. study using the revised PFS in breast cancer patients [17]. Results showed that the level of fatigue in our study population was lower than in the U.S. population.

The structure of the Dutch revised PFS was adequate, as shown by the observation that all items had higher correlations with their own subscale than with the three other subscales. Internal consistency for all subscales and the total scale of the PFS was high (Cronbach's $\alpha \geqslant 0.90$ ), confirming a previous U.S. validation study [17], as well as two non-U.S. studies conducted in France [21] and China [22]. In subanalyses (results not tabulated), we found high 
Table 2

Pearson's correlations of items, subscales, and total fatigue score of the Piper Fatigue Scale

\begin{tabular}{|c|c|c|c|c|c|}
\hline Item & Behavioral/severity & Affective meaning & Sensory & Cognitive/mood & Total \\
\hline Behavioral/severity & & & & & $0.92^{\mathrm{a}}$ \\
\hline 1. Fatigue distress & $0.85^{\mathrm{b}}$ & 0.78 & 0.74 & 0.61 & 0.83 \\
\hline 2. Interference with daily activities & $0.92^{\mathrm{b}}$ & 0.83 & 0.74 & 0.55 & 0.85 \\
\hline 3. Interference with socializing & $0.87^{\mathrm{b}}$ & 0.74 & 0.72 & 0.52 & 0.80 \\
\hline 4. Interference with sexual activity & $0.75^{\mathrm{b}}$ & 0.57 & 0.56 & 0.36 & 0.61 \\
\hline 5. Overall interference with enjoyable activities & $0.94^{\mathrm{b}}$ & 0.81 & 0.72 & 0.49 & 0.82 \\
\hline 6. Fatigue intensity/severity & $0.93^{\mathrm{b}}$ & 0.88 & 0.77 & 0.54 & 0.87 \\
\hline Affective meaning & & & & & $0.91^{\mathrm{a}}$ \\
\hline 7. Pleasant-unpleasant & 0.81 & $0.92^{\mathrm{b}}$ & 0.77 & 0.48 & 0.82 \\
\hline 8. Agreeable-Disagreeable & 0.80 & $0.90^{\mathrm{b}}$ & 0.72 & 0.57 & 0.84 \\
\hline 9. Protective-Destructive & 0.77 & $0.91^{\mathrm{b}}$ & 0.71 & 0.52 & 0.82 \\
\hline 10. Positive-Negative & 0.79 & $0.91^{\mathrm{b}}$ & 0.74 & 0.42 & 0.80 \\
\hline 11. Normal-Abnormal & 0.86 & $0.92^{\mathrm{b}}$ & 0.77 & 0.55 & 0.86 \\
\hline Sensory & & & & & $0.93^{\mathrm{a}}$ \\
\hline 12. Strong-Weak & 0.77 & 0.86 & $0.88^{\mathrm{b}}$ & 0.63 & 0.85 \\
\hline 13. Awake-Sleepy & 0.66 & 0.65 & $0.90^{\mathrm{b}}$ & 0.73 & 0.80 \\
\hline 14. Lively-Listless & 0.73 & 0.68 & $0.89^{\mathrm{b}}$ & 0.79 & 0.85 \\
\hline 15. Refreshed-Tired & 0.72 & 0.72 & $0.93^{\mathrm{b}}$ & 0.70 & 0.84 \\
\hline 16. Energetic-Unenergetic & 0.81 & 0.75 & $0.94^{\mathrm{b}}$ & 0.72 & 0.89 \\
\hline Cognitive/mood & & & & & $0.79^{\mathrm{a}}$ \\
\hline 17. Patient-Impatient & 0.45 & 0.46 & 0.66 & $0.82^{\mathrm{b}}$ & 0.63 \\
\hline 18. Relaxed-Tense & 0.56 & 0.61 & 0.76 & $0.86^{\mathrm{b}}$ & 0.75 \\
\hline 19. Exhilarated-Depressed & 0.56 & 0.56 & 0.81 & $0.86^{\mathrm{b}}$ & 0.75 \\
\hline 20. Able to concentrate-Unable to concentrate & 0.53 & 0.42 & 0.69 & $0.84^{\mathrm{b}}$ & 0.67 \\
\hline 21. Able to remember-Unable to remember & 0.36 & 0.24 & 0.39 & $0.72^{\mathrm{b}}$ & 0.48 \\
\hline 22. Able to think clearly-Unable to think clearly & 0.36 & 0.26 & 0.50 & $0.81^{\mathrm{b}}$ & 0.53 \\
\hline
\end{tabular}

a Correlation between scores on (1) the concerned subscale and (2) total fatigue scale.

b Values show corrected item-subscale correlations ("item-rest correlations").

correlations between individual items of the same subscale; for example, in the subscale behavioral/severity, we found between-item correlations varying from 0.40 to 0.87 ; in affective meaning, from 0.72 to 0.91 ; in sensory, 0.72 to 0.89 ; and in cognitive/mood, 0.35 to 0.86 . These high interitem correlations may indicate a certain degree of redundancy between PFS items.

In the patient group as a whole, corrected item-subscale correlations were $\geqslant 0.72$ (Table 2 ). In the French validation study [21], item-subscale correlations were lower (i.e., $\geqslant 0.4$ ), which could possibly be due to a more heterogeneous study population. In our population of lung cancer patients, the correlation between the total PFS and the subscale cognitive/mood was relatively low (0.67; Table 3), compared to the correlations of the total PFS and the other subscales $(0.82-0.89)$; the correlations of the subscale cognitive/mood with the subscales behavioral/severity $(0.30)$ and affective meaning $(0.20)$ were even lower.

When the concepts measured by individual items of the subscale cognitive/mood are considered in more detail, it appears that three items (17-19) focus on mood feelings and three items (20-22) on cognitive aspects. This may indicate that this subscale measures an aspect of fatigue distinct from the other subscales, especially in lung cancer patients. For breast cancer patients, the correlations of the subscale cognitive/mood with the subscales behavioral/ severity and affective meaning are higher, i.e. 0.67 and
0.71 , respectively; these correlations are more or less comparable with the U.S. study population [17].

The authors of the French validation study [21] reported that the cognitive/mood subscale appeared to group two separate dimensions. The study population of these authors $(n=229)$ included $14 \%$ lung and $41 \%$ breast cancer patients, all of whom underwent different treatment regimens. The Chinese validation study [22] was performed in only 17 patients with hematological malignancies. After minor adjustments and addition of one question, these authors retested the questionnaire after a 2-week interval; the reported test-retest reliability was 0.98 .

In our study, lung cancer patients had a significantly higher level of fatigue than did breast cancer patients, which is in agreement with earlier studies $[3,31,32]$ and thus supports construct validity of the Dutch PFS. Also, as expected, previous treatment with chemotherapy was associated with a significantly higher fatigue score on the subscale behavior/severity. Similar differences according to tumor type and previous treatment with chemotherapy were found for the general subscale of the MFI. These data support construct validity of the PFS. We did not include gender and age in our analysis of construct validity, because the literature is inconsistent on this matter [38-40].

As for criterion validity, correlations of the revised PFS with relevant subscales of the MFI and RSCL were reasonable $(0.37<r<0.84)$. The PFS subscales behavioral/severity 
Table 3

Pearson's correlations between total fatigue score and subscales of the Piper Fatigue Scale in lung and breast cancer patients, compared to breast cancer patients in the United States [17]

\begin{tabular}{|c|c|c|c|c|}
\hline & $\begin{array}{l}\text { Behavioral/ } \\
\text { severity }\end{array}$ & $\begin{array}{l}\text { Affective } \\
\text { meaning }\end{array}$ & Sensory & $\begin{array}{l}\text { Cognitive/ } \\
\text { mood }\end{array}$ \\
\hline \multicolumn{5}{|l|}{ Dutch study } \\
\hline \multicolumn{5}{|l|}{ Lung cancer $(n=30)$} \\
\hline Behavioral/severity & - & & & \\
\hline Affective meaning & $0.89^{\mathrm{a}}$ & - & & \\
\hline Sensory & $0.68^{\mathrm{a}}$ & $0.62^{\mathrm{a}}$ & - & \\
\hline Cognitive/mood & 0.30 & 0.20 & $0.66^{\mathrm{a}}$ & - \\
\hline Total fatigue scale & $0.88^{\mathrm{a}}$ & $0.82^{\mathrm{a}}$ & $0.89^{\mathrm{a}}$ & $0.67^{\mathrm{a}}$ \\
\hline \multicolumn{5}{|l|}{ Breast cancer $(n=34)$} \\
\hline Behavioral/severity & - & & & \\
\hline Affective meaning & $0.83^{\mathrm{a}}$ & - & & \\
\hline Sensory & $0.83^{\mathrm{a}}$ & $0.89^{\mathrm{a}}$ & - & \\
\hline Cognitive/mood & $0.67^{\mathrm{a}}$ & $0.71^{\mathrm{a}}$ & $0.82^{\mathrm{a}}$ & - \\
\hline Total fatigue scale & $0.91^{\mathrm{a}}$ & $0.94^{\mathrm{a}}$ & $0.95^{\mathrm{a}}$ & $0.86^{\mathrm{a}}$ \\
\hline \multicolumn{5}{|l|}{ U.S. study ${ }^{\mathrm{b}}$} \\
\hline \multicolumn{5}{|l|}{ Breast cancer $(n=382)$} \\
\hline Behavioral/severity & - & & & \\
\hline Affective meaning & 0.73 & - & & \\
\hline Sensory & 0.71 & 0.71 & - & \\
\hline Cognitive/mood & 0.67 & 0.62 & 0.76 & - \\
\hline Total fatigue scale & 0.90 & 0.88 & 0.90 & 0.86 \\
\hline
\end{tabular}

and affective meaning showed relatively high correlations $(>0.80)$ with the subscales general fatigue and physical fatigue of the MFI, which is not unexpected because these PFS subscales relate, respectively, to patients' experience of fatigue (i.e., its interference with daily activities), and to patients' perception of the fatigue they experience. As expected, the correlations of the subscale mental fatigue of the MFI correlated highest with subscale cognitive/mood of the PFS.

Comparison with a study in breast cancer patients in the United States [17] indicated that the U.S. patients were in general slightly more tired than our study population of breast cancer patients, even though both populations seemed to be comparable with regard to age, tumor stage, and previous treatment with surgery. However, a higher proportion of the U.S. breast cancer patients had been previously treated with radiotherapy $(50 \%$, vs. $0 \%$ for Dutch breast cancer patients) and/or chemotherapy (57\%, vs. $35 \%$ for Dutch breast cancer patients), which could explain

Table 4

Cronbach's $\alpha$ of total fatigue score and subscales of the Piper Fatigue Scale in lung and breast cancer patients, compared to published data [17] from breast cancer patients in the United States

\begin{tabular}{lclllll}
\hline & \multicolumn{4}{l}{ Cronbach's $\alpha$} \\
\cline { 3 - 5 } & & \multicolumn{2}{l}{ Dutch } & \\
\cline { 3 - 5 } Subscale & No. of items & All & Lung & Breast & U.S., breast \\
\hline Behavioral/severity & 6 & 0.94 & 0.90 & 0.93 & 0.92 \\
Affective meaning & 5 & 0.95 & 0.89 & 0.96 & 0.95 \\
Sensory & 5 & 0.95 & 0.88 & 0.98 & 0.96 \\
Cognitive/mood & 6 & 0.90 & 0.88 & 0.90 & 0.93 \\
Total fatigue scale & 22 & 0.97 & 0.93 & 0.97 & 0.97 \\
\hline
\end{tabular}

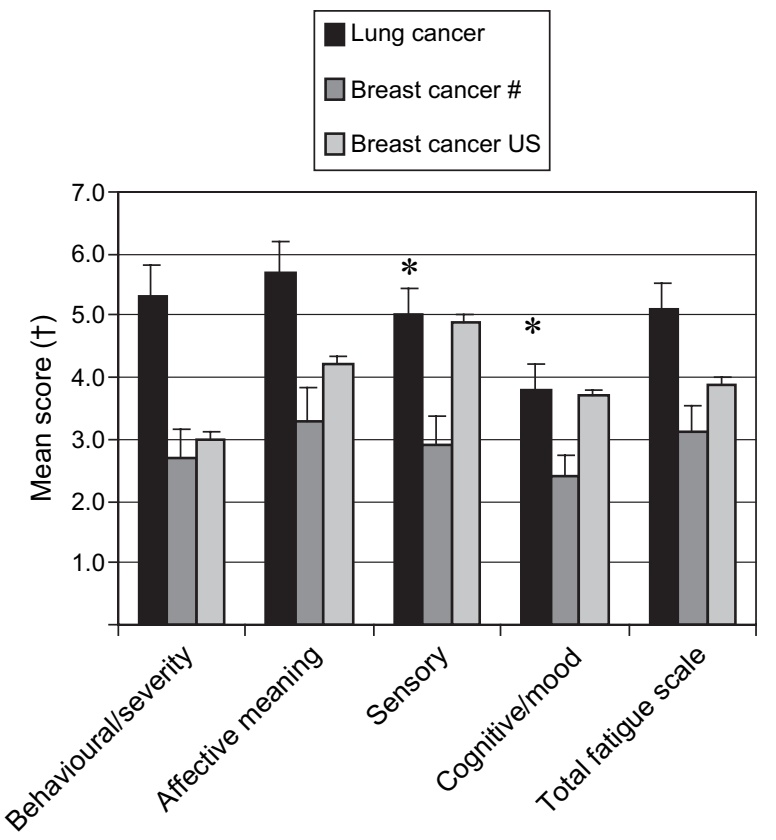

Fig. 1. Mean scores (with error bars to indicate standard error) of the total fatigue score and subscale scores of the Piper Fatigue Scale in Dutch lung and breast cancer patients, compared to breast cancer patients in the United States [17]. $\dagger$ Possible range $=0-10 . * P<0.01$ for subscales sensory and cognitive/mood in U.S. breast cancer patients vs. Dutch breast cancer patients. ${ }^{\#} P<0.01$ for total fatigue score and all subscales in breast cancer patients vs. lung cancer patients in Dutch population.

their higher level of fatigue. It should be noted that, due to the relatively low response in the U.S. study a (32\%), it remains uncertain whether the level of fatigue of the U.S. study population represented the fatigue of the study base. Also, patients from one culture might be more extrovert then patients from another culture, and might therefore be likely to express negative feelings more easily and/or with greater intensity. Because several studies have shown differences in QoL between countries [25,26,41-43], conclusions from studies on QoL (and fatigue) cannot be automatically transposed between countries and/or cultures.

Some questions were left unanswered by a considerable number of patients; for example, items 4 and 10 were unanswered by $14 \%$ and $11 \%$ of patients, respectively. This may be due either to the sensitivity of a specific item (item 4 refers to sexual activity) or to difficulties in understanding the concept of a specific item (item 10, evaluating fatigue in terms of 'positive' vs. 'negative'). Because corrected item-subscale correlations were generally high, and because there were no subjects with more than a single missing item on the same subscale, the replacement of missing values by the average score of the same individual on that subscale would have little effect. We therefore do not expect that the presence of missing items has affected our results.

Strengths of the present study are the homogeneous study population and the high level of participation of subjects; however, limitations are the relatively small number of subjects; the restriction to only two tumor types; the fact 
Table 5

Criterion validity, expressed as Pearson's correlations ${ }^{\mathrm{a}}$ between subscales of the Piper Fatigue Scale with the Multidimensional Fatigue Inventory (MFI) and the Rotterdam Symptom Checklist (RSCL)

\begin{tabular}{|c|c|c|c|c|c|}
\hline Subscale & $\begin{array}{l}\text { Behavioral/ } \\
\text { severity }\end{array}$ & $\begin{array}{l}\text { Affective } \\
\text { meaning }\end{array}$ & Sensory & $\begin{array}{l}\text { Cognitive/ } \\
\text { mood }\end{array}$ & Total \\
\hline \multicolumn{6}{|l|}{ MFI } \\
\hline General fatigue & 0.80 & 0.84 & 0.80 & 0.62 & 0.84 \\
\hline Physical fatigue & 0.81 & 0.80 & 0.78 & 0.56 & 0.81 \\
\hline Reduced activity & 0.72 & 0.63 & 0.66 & 0.58 & 0.70 \\
\hline $\begin{array}{l}\text { Reduced } \\
\text { motivation }\end{array}$ & 0.58 & 0.51 & 0.56 & 0.58 & 0.60 \\
\hline Mental fatigue & 0.44 & 0.37 & 0.49 & 0.58 & 0.49 \\
\hline \multicolumn{6}{|l|}{ RSCL } \\
\hline $\begin{array}{l}\text { Psychological } \\
\text { distress }\end{array}$ & 0.46 & 0.44 & 0.54 & 0.63 & 0.54 \\
\hline Activity level & 0.69 & 0.62 & 0.54 & 0.40 & 0.62 \\
\hline $\begin{array}{l}\text { Overall quality } \\
\text { of life }\end{array}$ & 0.78 & 0.74 & 0.71 & 0.51 & 0.74 \\
\hline
\end{tabular}

a All $P$-values $<0.01$.

that only cancer patients after surgery, and prior to radiotherapy, were included; and the lack of longitudinal data regarding, for instance, sensitivity to changes induced by therapy (i.e., responsiveness). Furthermore, we cannot exclude the possibility that the omission of the physical symptom distress subscale of the RSCL from our questionnaire could have influenced the scores on the remaining RSCL subscales to some extent.

In conclusion, the psychometric properties of the Dutch version of the revised PFS, as tested in lung and breast cancer patients preceding radiotherapy, were satisfactory. Thus, the revised PFS may be a useful instrument in cross-cultural comparisons, especially when comparing fatigue in cancer patients at different disease and treatment stages in the United States and other countries. Further validation studies in different and larger populations of cancer patients, at different stages of disease and therapy would be nonetheless valuable.

\section{References}

[1] Richardson A. Measuring fatigue in patients with cancer. Support Care Cancer 1998;6:94-100.

[2] Piper BF, Lindsey AM, Dodd MJ. Fatigue mechanisms in cancer patients: developing nursing theory. Oncol Nurs Forum 1987;14: $17-23$.

[3] Glaus A. Fatigue in patients with cancer: analysis and assessment. Recent Results Cancer Res 1998;145:i-xi. 1-172.

[4] Richardson A. Fatigue in cancer patients: a review of the literature. Eur J Cancer Care (Engl) 1995;4:20-32.

[5] Wu HS, McSweeney M. Measurement of fatigue in people with cancer. Oncol Nurs Forum 2001;28:1371-84; quiz 1385-6.

[6] Morrow GR, Shelke AR, Roscoe JA, Hickok JT, Mustian K. Management of cancer-related fatigue. Cancer Invest 2005;23:229-39.

[7] Donovan KA, Jacobsen PB, Andrykowski MA, Winters EM, Balducci L, Malik U, Kenady D, McGrath P. Course of fatigue in women receiving chemotherapy and/or radiotherapy for early stage breast cancer. J Pain Symptom Manage 2004;28:373-80.

[8] Smets EM, Visser MR, Willems-Groot AF, et al. Fatigue and radiotherapy: (A) experience in patients undergoing treatment. Br J Cancer 1998;78:899-906.
[9] Winningham ML, Nail LM, Burke MB, Brophy L, Cimprich B, Jones LS, Pickard-Holley S, Rhodes V, St Pierre B, Beck S, et al. Fatigue and the cancer experience: the state of the knowledge. Oncol Nurs Forum 1994;21:23-36.

[10] Monga U, Kerrigan AJ, Thornby J, Monga TN. Prospective study of fatigue in localized prostate cancer patients undergoing radiotherapy. Radiat Oncol Investig 1999;7:178-85.

[11] King KB, Nail LM, Kreamer K, Strohl RA, Johnson JE. Patients' descriptions of the experience of receiving radiation therapy. Oncol Nurs Forum 1985;12:55-61.

[12] Borthwick D, Knowles G, McNamara S, Dea RO, Stroner P. Assessing fatigue and self-care strategies in patients receiving radiotherapy for non-small cell lung cancer. Eur J Oncol Nurs 2003;7:231-41.

[13] Faithfull S. Fatigue in patients receiving radiotherapy. Prof Nurse 1998;13:459-61.

[14] Visser MR, Smets EM. Fatigue, depression and quality of life in cancer patients: how are they related? Support Care Cancer 1998;6:101-8.

[15] Irvine D, Vincent L, Graydon JE, Bubela N, Thompson L. The prevalence and correlates of fatigue in patients receiving treatment with chemotherapy and radiotherapy: a comparison with the fatigue experienced by healthy individuals. Cancer Nurs 1994;17:367-78.

[16] Curt GA. Fatigue in cancer. BMJ 2001;322:1560.

[17] Piper BF, Dibble SL, Dodd MJ, Weiss MC, Slaughter RE, Paul SM. The revised Piper Fatigue Scale: psychometric evaluation in women with breast cancer. Oncol Nurs Forum 1998;25:677-84.

[18] Beach P, Siebeneck B, Buderer NF, Ferner T. Relationship between fatigue and nutritional status in patients receiving radiation therapy to treat lung cancer. Oncol Nurs Forum 2001;28:1027-31.

[19] Fu MR, Anderson CM, McDaniel R, Armer J. Patients' perceptions of fatigue in response to biochemotherapy for metastatic melanoma: a preliminary study. Oncol Nurs Forum 2002;29:961-6.

[20] Payne JK. The trajectory of fatigue in adult patients with breast and ovarian cancer receiving chemotherapy. Oncol Nurs Forum 2002;29: 1334-40.

[21] Gledhill JA, Rodary C, Mahe C, Laizet C. French validation of the revised Piper Fatigue Scale [In French]. Rech Soins Infirm 2002 $\operatorname{Mar}(68): 50-65$.

[22] So WK, Dodgson J, Tai JW. Fatigue and quality of life among chinese patients with hematologic malignancy after bone marrow transplantation. Cancer Nurs 2003;26:211-9.

[23] Biswal BM, Kumaraswamy N, Mukhtar F. Prevalence of fatigue among cancer patients undergoing external radiotherapy. Southeast Asian J Trop Med Public Health 2004;35:463-7.

[24] Yates P, Aranda S, Hargraves M, Mirolo B, Clavarino A, McLachlan S, Skerman H. Randomized controlled trial of an educational intervention for managing fatigue in women receiving adjuvant chemotherapy for early-stage breast cancer. J Clin Oncol 2005;23: 6027-36.

[25] de Haes JC, Olschewski M. Quality of life assessment in a crosscultural context: use of the Rotterdam Symptom Checklist in a multinational randomised trial comparing $\mathrm{CMF}$ and Zoladex (Goserlin) treatment in early breast cancer. Ann Oncol 1998;9:745-50.

[26] Forjaz MJ, Guarnaccia CA. A comparison of Portuguese and American patients with hematological malignancies: a cross-cultural survey of health-related quality of life. Psychooncology 2001;10:251-8.

[27] Juarez G, Ferrell B, Borneman T. Cultural considerations in education for cancer pain management. J Cancer Educ 1999;14:168-73.

[28] Pijls-Johannesma MCG, Pijpe A, Kempen GIJM, Lambin P, Dagnelie PC. Health related quality of life assessment instruments: a prospective study on preference and acceptability among cancer patients referred for radiotherapy. Eur J Cancer 2005;41:2250-6.

[29] Guillemin F, Bombardier C, Beaton D. Cross-cultural adaptation of health-related quality of life measures: literature review and proposed guidelines. J Clin Epidemiol 1993;46:1417-32.

[30] Martin W, Tops GAJ, editors. The greater English-Dutch dictionary [Groot Woordenboek Engels-Nederlands]. 2nd ed. Utrecht: Van Dale Lexicografie; 1989. 
[31] Hurny C, Bernhard J, Joss R, Schatzmann E, Cavalli F, Brunner K, Alberto P, Senn HJ, Metzger U; The Swiss Group for Clinical Cancer Research (SAKK). "Fatigue and malaise" as a quality-of-life indicator in small-cell lung cancer patients. Support Care Cancer 1993;1: $316-20$.

[32] Smets EM, Garssen B, Cull A, de Haes JC. Application of the Multidimensional Fatigue Inventory (MFI-20) in cancer patients receiving radiotherapy. Br J Cancer 1996;73:241-5.

[33] Iop A, Manfredi AM, Bonura S. Fatigue in cancer patients receiving chemotherapy: an analysis of published studies. Ann Oncol 2004;15: $712-20$.

[34] de Jong N, Courtens AM, Abu-Saad HH, Schouten HC. Fatigue in patients with breast cancer receiving adjuvant chemotherapy: a review of the literature. Cancer Nurs 2002;25:283-97; quiz 298-9.

[35] Smets EM, Garssen B, Bonke B, De Haes JC. The Multidimensional Fatigue Inventory (MFI) psychometric qualities of an instrument to assess fatigue. J Psychosom Res 1995;39:315-25.

[36] de Haes JCM, Olschewski M, Fayers P, Visser MRM, Cull A, Hopwood P, Sanderman R. Measuring the quality of life of cancer patients with the Rotterdam Symptom Checklist (RSCL): a manual. Groningen: Northern Centre for Healthcare Research ( $\mathrm{NCH})$, University of Groningen; 1996 [Available at http://www.med.rug.nl/nch/ rscl.pdf].
[37] de Haes JC, van Knippenberg FC, Neijt JP. Measuring psychological and physical distress in cancer patients: structure and application of the Rotterdam Symptom Checklist. Br J Cancer 1990;62:1034-8.

[38] Jereczek-Fossa BA, Marsiglia HR, Orecchia R. Radiotherapy-related fatigue. Crit Rev Oncol Hematol 2002;41:317-25.

[39] Miaskowski C. Gender differences in pain, fatigue, and depression in patients with cancer. J Natl Cancer Inst Monogr 2004;32:139-43.

[40] Hickok JT, Roscoe JA, Morrow GR, Mustian K, Okunieff P, Bole CW. Frequency, severity, clinical course, and correlates of fatigue in 372 patients during 5 weeks of radiotherapy for cancer. Cancer 2005;104:1772-8.

[41] Hurny C, Bernhard J, Gelber RD, Coates A, Castiglione M, Isley M, Dreher D, Peterson H, Goldhirsch A, Senn HJ; The International Breast Cancer Study Group. Quality of life measures for patients receiving adjuvant therapy for breast cancer: an international trial. Eur J Cancer 1992;28:118-24.

[42] Collings JA. International differences in psychosocial well-being: a comparative study of adults with epilepsy in three countries. Seizure 1994;3:183-90.

[43] Erbil P, Razavi D, Farvacques C, Bilge N, Paesmans M, Van Houtte P. Cancer patients psychological adjustment and perception of illness: cultural differences between Belgium and Turkey. Support Care Cancer 1996;4:455-61. 